\title{
FORMULATION AND EVALUATION OF CROCONAZOL HYDROCHLORIDE TOPICAL GELS
}

\author{
M. EL-Badry* ${ }^{1}$ and N. A. Hussein ${ }^{2}$ \\ ${ }^{1}$ Department of Pharmaceutics, Faculty of Pharmacy and ${ }^{2}$ Department of Botany, Faculty of \\ Science, Assiut University, 71526 Assiut, Egypt
}

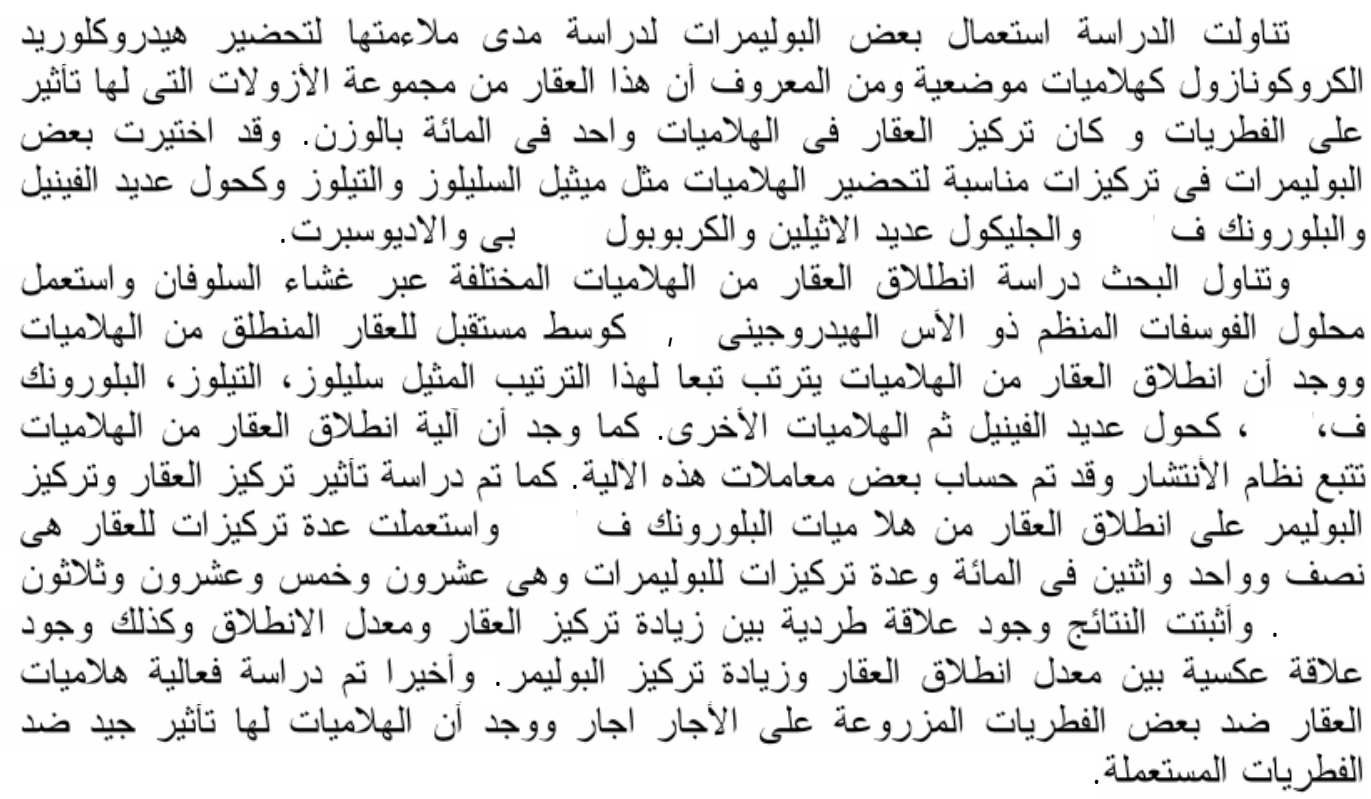

This study was designed to evaluate different polymers for their suitability as a vehicles for topical drug delivery systems. Croconazol hydrochloride is an azol derivative used as antimycotic agent. It was incorporated in this vehicles as a gel forms in a concentration of $1.0 \%$ $w / w$. Polymers used in this study are methylcellulose (MC), Tylose (Ty), Polyvinyl alcohol (PVA), Pluronic F-127 (pl. F-127), Polyethylene glycol (PEG), Carbopol 974P (Carb.) and Eudispert $\mathrm{mv}$. (Eud). They were used in a suitable concentration for gel formulation.

In-vitro release characteristics of the drug from different gels were carried out using dialysis membrane in phosphate buffer $\mathrm{pH}$ 5.2. The release data were treated with various kinetic principles to assess the relevant parameters. The general rank order of Croconazol hydrochloride release from the prepared gel were $M C>T y>p l . F-127>P V A>C a r b>$ Eud $>$ PEG. The results showed that, the release of drug from the prepared gels obeyed the diffusion model (Higuchi's equation). Some kinetic parameters were calculated such as diffusion coefficient, permeability coefficient and the partition coefficient. The results indicated a direct dependence of the release rate on the diffusion coefficient. The influence of initial drug concentration $(0.5,1.0$ and $2.0 \% \mathrm{w} / \mathrm{w})$, and $\mathrm{pl} F-127$ concentration $(20,25,30 \% \mathrm{w} / \mathrm{v})$ on the release patterns was studied. The obtained data revealed an inverse correlation between the drug release rate and the pluronic F-127 concentration and a direct correlation between the drug release rate and the initial drug concentration. The anti-fungal activity of the different gel formulations was evaluated by agar-cup plate technique using five fungal species. The results obtained indicated that, all gel formulations have good anti-fungal activities. 


\section{INTRODUCTION}

Topical products are important class of drug delivery systems and their uses in the therapy become more widespread. The purpose of topical dosage form is to conveniently deliver drugs to localized area of the skin. ${ }^{1}$

Superficial fungal infections such as dermatophytosis or candidiasis are increasing and represent common dermatological problems. The therapeutic efficacy of a topically applied drug used for dermatological diseases is not always as complete as desirable because it depends on the ability of the drug to penetrate the skin and accumulate in the deeper layers of the skin. ${ }^{2}$ Dermatophytes are a group of closely related fungi that have capacity to invade keratinized tissues (skin, hair, and nails) of human and animals to produce a harmful infection. Many anti-fungal peptides produced by some organisms or synthesized compound are active against the growth of yeast and filamentous fungi. ${ }^{3-5}$

Croconazol hydrochloride is a synthetic imidazole derivative (phenyl vinyl derivative) It is a potent topical anti-fungal agent. It is active against dermatophytes (the causative organisms of tinea infections) and yeasts (Candida albicans). ${ }^{6}$ Croconazol hydrochloride is water insoluble drug, so hydrogel may be an excellent vehicle for the topical delivery of this drug. Many authors used hydrogel bases such as Carbopol, $^{7} \quad$ Poloxamers$^{8} \quad$ Cellulose derivatives ${ }^{9}$ and Eudispert $^{10}$ as topical drug delivery systems.

The purpose of the present study is to formulate Croconazol hydrochloride in different gel forms, to determine the in-vitro release of the drug from these formulations, to study the effect of initial drug concentration and polymer concentration on drug release profile and lastly to study the anti-fungal activity of these formulations.

\section{EXPERIMENTAL}

\section{Materials}

Croconazol hydrochloride (Shionogi, Japan), Methylcellulose (Dow Chemical Co. USA), Carbopol 974P (BF. Goodrich Chem. Co. USA), Eudispert mv (Rhom Pharma, GmbH, Darmstadt, Germany), Pluronic F-127
(BASF, Ludwigshafen, Germany), Tylose (methylhydroxyethylcellulose) (Clariant $\mathrm{GmbH}$, Wiesbaden, Germany), Polyethylene glycol, MW 600, 1000 (Merck-Schuchardt, Munchen, Germany), polyvinyl alcohol (BDH, England). Triethanolamine, sodium dihydrogen orthophosphate (EL-Naser Chemical Co. Egypt). Semipermeable Fisher cellophane membrane No. 30/32 (Fisher Sci. Co. London, England). Sabouraud-dextrose agar (Oxoid, England). Miconazol cream (MUP, Egypt containing miconazol nitrate $2 \% \mathrm{w} / \mathrm{w}$ ) was used as control in the microbiological study. All other chemicals are of pharmaceutical grades.

\section{Apparatus}

Electronic balance (Percisa 205A, Oerlikon AG, Zurich, Switzerland), Magnetic stirrer with hotplate (Gallenkamp, England), pH-meter (Jenway, Ltd. UK), UVspectrophotometer (Schimadzu, Japan).

\section{Methods \\ Preparation of gels}

Croconazol hydrochloride gels $(1.0 \%$ w/w) were prepared by different methods according to the polymer used as the following.

\section{Preparation of pluronic F-127 gel}

Pluronic F-127 gel $(25 \% \quad \mathrm{w} / \mathrm{v})$ was prepared by the cold method described by Schmolka. ${ }^{11}$ The weighed amount of the polymer was slowly added to water with gentle mixing. The mixture was left in refrigerator $\left(4^{\circ}\right)$ overnight to complete dissolution of the polymer. After the formation of a clear viscous solution, a solution of the drug was added to the polymer solution and mixed very gently with a glass rod. The solution was left at room temperature until a clear gel is formed.

\section{Preparation of Carbopol 974P gel}

Carbopol 974P gel $(2.0 \% \quad \mathrm{w} / \mathrm{v})$ was prepared adopting the method of French et. $a l .{ }^{12}$ Carbopol was added to the water portion wise with gentle mixing. After complete addition of the polymer and mixing, the drug solution was added. The gel was spontaneously formed by addition of two millilitres of triethanolamine. 


\section{Preparation of Eudispert mv gel}

Eudispert $\mathrm{mv}(5.0 \% \mathrm{w} / \mathrm{v})$ was sprinkled gradually into water with gentle mixing, the drug solution was added. Two millilitres of triethanolamine were added until a gel is obtained.

\section{Preparation of methylcellulose and Tylose gels}

The weighed amount of the powder (methylcellulose $5.0 \% \mathrm{w} / \mathrm{v}$, Tylose $2.0 \% \mathrm{w} / \mathrm{v}$ ) was added gently to hot water. Stirring was continued to prevent the formation of lumps. The drug solution was added, then left overnight in a refrigerator $\left(4^{\circ}\right)$ to complete solubility and gel formation.

\section{Preparation of polyvinyl alcohol gel}

The weighed amount of polyvinyl alcohol $(15 \% \mathrm{w} / \mathrm{v})$ was added to water and mixed very gently till complete solubilization of the powder and gel formation, then the drug solution was added.

\section{Preparation of polyethylene glycol gel}

The polyethylene glycol gel was prepared using the heat and mechanical incorporation method. Polyethylene glycol of MW 1000 and 600 at a ratio of $1: 2 \mathrm{w} / \mathrm{w}$ were placed in a beaker and heated on water bath till complete mixing and stirred until congealed. The drug solution was mixed gently to produce the final gel.

\section{In-vitro release of Croconazol hydrochloride from different gel formulations}

In-vitro release of the drug from different gel formulations was evaluated using standard cellophane membrane stretched at the end of the dialysis cell $(2.5 \mathrm{~cm}$ in diameter and $10 \mathrm{~cm}$ in length) that contain $1.0 \mathrm{gm}$ of gel (donor compartment). The acceptor compartment composed of glass beaker $(250 \mathrm{ml})$ containing $100 \mathrm{ml}$ of phosphate buffer $\mathrm{pH} 5.2$ as release medium, and kept at $37^{\circ} \pm 0.5$. The content of the beaker was stirred using magnetic stirrer with hotplate $(50 \mathrm{rpm})$.

Aliquots $(5.0 \mathrm{ml})$ were withdrawn at time intervals and measured spectrophotometrically at $\lambda \max 284 \mathrm{~nm}^{13}$ against blank similarly treated. The release medium kept constant by adding a fresh buffer to the acceptor compartment.
All experiments were carried out in triplicate and the average values were calculated.

\section{Mathematical treatment of the data}

The in-vitro release data of Croconazol hydrochloride from the investigated gel formulations was linearized according to zeroorder, first-order and diffusion models kinetics. The permeation parameters of the drug (permeability coefficient $\mathrm{p}_{\mathrm{m}}$, diffusion coefficient, $\mathrm{D}_{\text {app }}$, and partition coefficient $\mathrm{k}_{\mathrm{p}}$ ) were calculated according the following equations:

$$
\begin{array}{ll}
\mathrm{Q}=2 \mathrm{C}_{\mathrm{o}} \sqrt{\mathrm{Dt}} / \pi & \text { Eq. } 1 \\
\mathrm{D}=\left(\text { slope } / 2 \mathrm{C}_{\mathrm{o}}\right)^{2} \pi & \text { Eq. } 2 \\
\mathrm{P}=(\mathrm{k} . \mathrm{D}) / \mathrm{L} & \text { Eq. } 3
\end{array}
$$

Where:

Q: the amount of drug released per unit area $\left(\mathrm{mg} / \mathrm{cm}^{2}\right)$.

$\mathrm{C}_{0:}$ the initial drug concentration (mg).

$\mathrm{t}$ : time interval (hr.).

D: Diffusion coefficient.

P: permeability coefficient.

K: partition coefficient.

$\mathrm{L}$ : thickness of membrane $(\mathrm{cm})$.

The release profile was constructed by plotting the cumulative amount of the released drug per unit area $\left(\mathrm{mg} / \mathrm{cm}^{2}\right)$ versus $\mathrm{t}^{1 / 2}$. The diffusion coefficient was calculated from the slope obtained, $\mathrm{C}_{\mathrm{o}}$ was the initial concentration of the drug in the vehicle. The partition coefficient $(\mathrm{k})$ was calculated from $\mathrm{P}$ and $\mathrm{D}$ and the thickness of membrane (equation 3 ).

\section{Anti-fungal activities}

Agar-cup diffusion technique was adopted. ${ }^{14}$ Five fungal species were used, some of them are pathogenic for human and animals, namely, Aspergillus flauus, Candida albicans, Chrysosporium tropicum (keratinophyte), Penicillium chrysogenum and Trichophyton rubrum (dermatophyte) were cultivated on Sabouraud-dextrose agar. After solidification, 1 $\mathrm{cm}$ holes were made and filled with accurately weighed $0.25 \mathrm{gm}$ of gel formulations or control (miconazol cream). The plates were incubated at $28^{\circ}$ for 3 days. The inhibition zones around the perforations were measured in $\mathrm{mm}$. 


\section{RESULTS AND DISCUSSION}

\section{In-vitro release of Croconazol hydrochloride from different gel formulations}

The results of the percentage release of Croconazol hydrochloride from various gel formulations, evaluated through four hours period, are exhibited in Figure 1. The general rank order of the release of the drug was observed to be MC gel > Ty > pl. F$127>$ PVA > Carb. > Eud and finally PEG gel (Fig. 1).

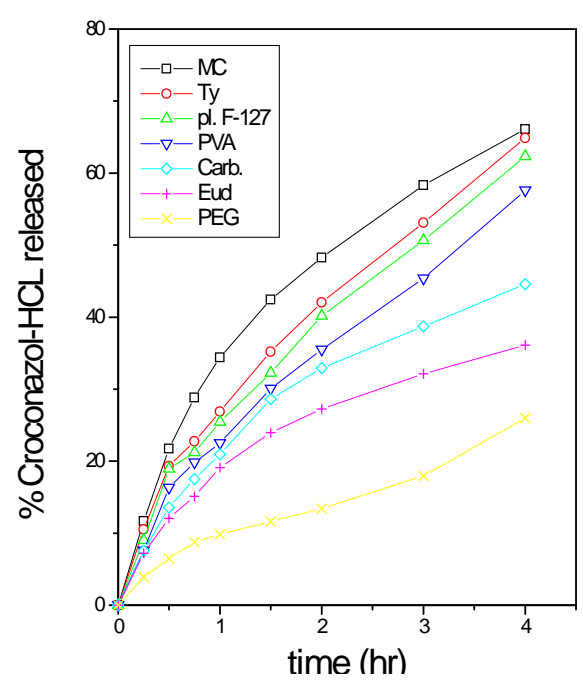

Fig. 1: In-vitro release profile of Croconazol hydrochloride $(1 \% \mathrm{w} / \mathrm{w})$ from different topical gel formulations.

\section{Effect of vehicle on drug release}

It is well known that, the nature of the vehicle has a great influence on drug release. In the present study, different hydrogel bases with different polymer structure were used to compare the release profile of the drug from these vehicles. The diffusion of the drug from any base depends on the nature and composition of the individual base. ${ }^{15}$ The cellulose derivative and pl. F-127 exhibited a superior drug release which might be related to vehicle nature. Croconazol hydrochloride release from these gel formulations (after four hours) was 1.5, 2, 3-folds higher than Carb, Eud and PEG gel respectively, that may be reflect the affinity of the drug to the gel base.

\section{Kinetic of the in-vitro release studies}

Various kinetic models, namely zeroorder, first-order fashions and Higuchi diffusion mechanism were applied to obtain the best fit of the data. The confirmation between the different mechanisms was dependant upon the correlation coefficient (r) Table 1. The results revealed that, the release pattern of the drug from the tested formulations followed the Higuchi diffusion model $(r=0.974-0.999)$.

Table 2 represents the kinetic parameters of diffusion mechanism of Croconazol hydrochloride released from different gel formulations. From Table 2, it was shown that, cellulose derivative gels and pl. F-127 gel have higher diffusion coefficient $\left(D_{\text {app }}\right)$ than other

Table 1: Correlation coefficient (r) after mathematical treatments of the release data of Croconazol hydrochloride from different gel formulations according to zero-order, first-order and diffusion mechanisms.

\begin{tabular}{||l|c|c|c|}
\hline \multicolumn{1}{|c|}{ Polymer used } & $\begin{array}{c}\text { Zero-order } \\
{ }^{*}(\mathrm{r})\end{array}$ & $\begin{array}{c}\text { First-order } \\
{ }^{*}(\mathrm{r})\end{array}$ & $\begin{array}{c}\text { Diffusion } \\
{ }^{*}(\mathrm{r})\end{array}$ \\
\hline Methylcellulose & 0.943 & 0.841 & 0.986 \\
\hline Tylose & 0.990 & 0.943 & 0.997 \\
\hline Pluronic F-127 & 0.986 & 0.896 & 0.999 \\
\hline Polyvinyl alcohol & 0.968 & 0.895 & 0.994 \\
\hline Carbopol 974P & 0.977 & 0.935 & 0.995 \\
\hline Eduspirt mv & 0.962 & 0.882 & 0.994 \\
\hline Polyethylene glycol & 0.918 & 0.939 & 0.974 \\
\hline
\end{tabular}

*r : Correlation coefficient. 
Table 2: The kinetic parameters of diffusion mechanism of Croconazol hydrochloride released from different topical gel formulations.

\begin{tabular}{|c|c|c|c|}
\hline Polymer used & $\begin{array}{c}\mathrm{D}_{\text {app }} \times 10^{-3} \\
\left(\mathrm{~cm}^{2} / \mathrm{sec}\right)\end{array}$ & $\begin{array}{c}\mathrm{P}_{\mathrm{m}} \times 10^{-2} \\
(\mathrm{~cm} / \mathrm{sec})\end{array}$ & $\mathrm{K}_{\mathrm{p}} \times 10^{-3}$ \\
\hline Methylcellulose & $8.082 \times 10^{-3}$ & $3.08 \times 10^{-2}$ & $3.810 \times 10^{-3}$ \\
\hline Tylose & $7.655 \times 10^{-3}$ & $3.47 \times 10^{-2}$ & $4.533 \times 10^{-3}$ \\
\hline Pluronic F-127 & $7.558 \times 10^{-3}$ & $3.26 \times 10^{-2}$ & $4.323 \times 10^{-3}$ \\
\hline Polyvinyl alcohol & $6.829 \times 10^{-3}$ & $3.43 \times 10^{-2}$ & $5.022 \times 10^{-3}$ \\
\hline Carbopol 974P & $6.430 \times 10^{-3}$ & $4.48 \times 10^{-2}$ & $6.980 \times 10^{-3}$ \\
\hline Eudispert mv & $5.864 \times 10^{-3}$ & $5.54 \times 10^{-2}$ & $9.440 \times 10^{-3}$ \\
\hline Polyethylene glycol & $4.842 \times 10^{-3}$ & $7.71 \times 10^{-2}$ & $15.90 \times 10^{-3}$ \\
\hline
\end{tabular}

$\mathrm{D}_{\text {app }}$ : Diffusion coefficient $\left(\mathrm{cm}^{2} / \mathrm{sec}\right)$.

$\mathrm{K}_{\mathrm{p}} \quad$ : Partition coefficient.
$\mathrm{P}_{\mathrm{m}}$ : Permeability coefficient $(\mathrm{cm} / \mathrm{sec})$.

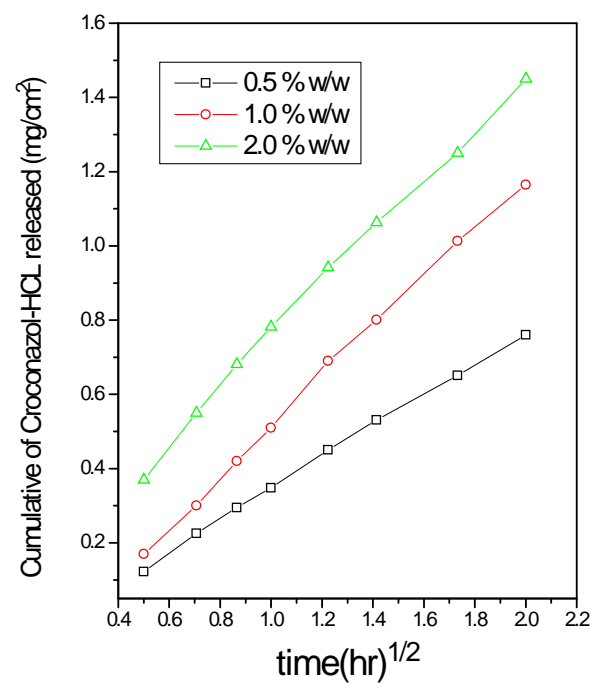

Fig. 2: In-vitro release profiles of Croconazol hydrochloride from Pluronic F-127 gel $(25 \% \mathrm{w} / \mathrm{v})$ as a function of initial drug concentration.

\section{Effect of polymer concentration of the gel on the release of the drug}

The release profile of Croconazol hydrochloride $(1.0 \% \mathrm{w} / \mathrm{w})$ from the gel bases composed of $20 \%, 25 \%$ and $30 \%$ w/v pl. F-127 presented in Figure 3. In general, it can be seen as the concentration of pl. F-127 increased the diffusion coefficient of the drug decreased Table 3, $\left(7.65 \times 10^{-3}, 7.558 \times 10^{-3}\right.$ and $6.86 \times 10^{-3}$ $\mathrm{cm}^{2} / \mathrm{sec}$ for $20 \%, 25 \%$, and $30 \% \mathrm{w} / \mathrm{v}$ ) polymer concentration respectively. EL-Gibaly et al. ${ }^{18}$ reported similar results on their study on clotrimazole release from different gel formulation. 


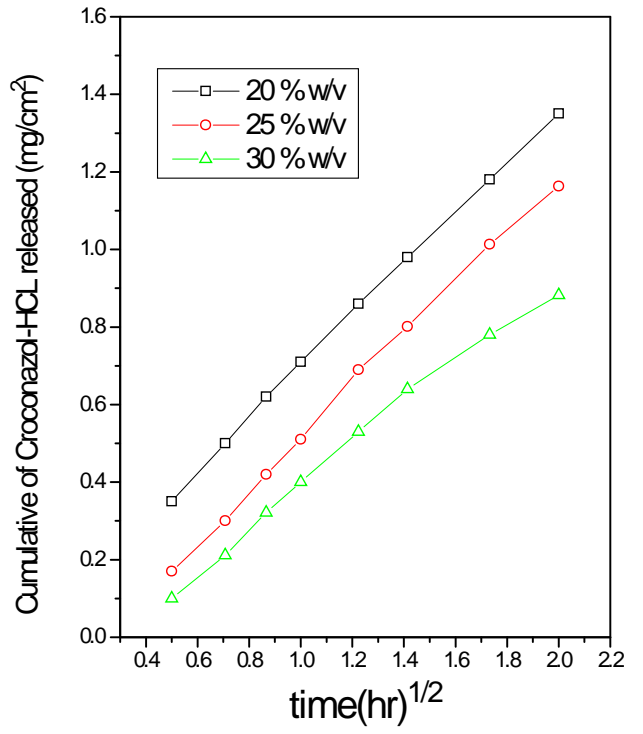

Fig. 3: In-vitro release profile of Croconazol hydrochloride $(1 \% \mathrm{w} / \mathrm{w})$ from pluronic F127 gel as a function of polymer concentration.

\section{Anti-fungal activity of Croconazol hydro- chloride gel}

The anti-fungal activity of the gel formulations of Croconazol hydrochloride was carried out by measuring the inhibition zone in $(\mathrm{mm})$ and compared by the effect of miconazol gel (MUP, Egypt) as control. Table 4 displayed the inhibition zone of Croconazol hydrochloride gel formulations. All the tested formulations gave a good inhibition zone. From the obtained results, it appeared that, all gel formulations had a high inhibitory effect on the most tested fungal species, but had a moderate inhibitory effect against Candida albicans. Also, It is observed that, the inhibition zone $(\mathrm{mm})$ of Croconazol hydrochloride gels was larger than the control gel. In addition, the control gel was inactive (no inhibition zone) against Penicillium chrysogenum, but all Croconazol hydrochloride gel had highly inhibition activity. Lastly, from the obtained results, it is seemed that, there was a slight difference in inhibition activity of the different gel formulations, but with the same rank order of the in-vitro release of the drug from the gel forms, with an exception, PEG gel.

Table 3: Effect of drug concentration and polymer concentration on the Kinetic parameters of diffusion of Croconazol hydrochloride from pl. F-127 gel formulations.

\begin{tabular}{|c|c|c|c|}
\hline & $\begin{array}{c}\mathrm{D}_{\text {app }} \\
\left(\mathrm{cm}^{2} / \mathrm{sec}\right)\end{array}$ & $\begin{array}{c}\mathrm{P}_{\mathrm{m}} \\
(\mathrm{cm} / \mathrm{sec})\end{array}$ & $\mathrm{K}_{\mathrm{p}}$ \\
\hline $\begin{array}{c}\text { - drug concentration } \\
0.5 \% \mathrm{w} / \mathrm{w}\end{array}$ & $6.110 \times 10^{-3}$ & $5.26 \times 10^{-2}$ & $8.610 \times 10^{-3}$ \\
\hline $1.0 \% \mathrm{w} / \mathrm{w}$ & $7.558 \times 10^{-3}$ & $3.26 \times 10^{-2}$ & $4.323 \times 10^{-3}$ \\
\hline $2.0 \% \mathrm{w} / \mathrm{w}$ & $8.000 \times 10^{-3}$ & $3.432 \times 10^{-2}$ & $4.290 \times 10^{-3}$ \\
\hline $\begin{array}{c}\text { Polymer concentration } \\
20 \% \mathrm{w} / \mathrm{v}\end{array}$ & $7.654 \times 10^{-3}$ & $2.96 \times 10^{-2}$ & $3.867 \times 10^{-3}$ \\
\hline $25 \% \mathrm{w} / \mathrm{v}$ & $7.558 \times 10^{-3}$ & $3.26 \times 10^{-2}$ & $4.323 \times 10^{-3}$ \\
\hline $30 \% \mathrm{w} / \mathrm{v}$ & $6.861 \times 10^{-3}$ & $4.53 \times 10^{-2}$ & $6.610 \times 10^{-3}$ \\
\hline \hline
\end{tabular}

$\mathrm{D}_{\text {app. }}$ : Diffusion coefficient $\left(\mathrm{cm}^{2} / \mathrm{sec}\right)$.

$\mathrm{P}_{\mathrm{m}}$ : Permeability coefficient $(\mathrm{cm} / \mathrm{sec})$.

$\mathrm{K}_{\mathrm{p}} \quad$ : Partition coefficient. 
Table 4: Anti-fungal activity of different Croconazol hydrochloride gel formulations.

\begin{tabular}{|c|c|c|c|c|c|}
\hline \multirow{2}{*}{ Gel type } & \multicolumn{5}{|c|}{$\begin{array}{l}\text { Inhibition zone (mm) using the following different fungal } \\
\text { speices }\end{array}$} \\
\hline & $\begin{array}{l}\text { Aspergilus } \\
\text { Flauus }\end{array}$ & $\begin{array}{l}\text { Candida } \\
\text { albicans }\end{array}$ & $\begin{array}{l}\text { Chryso. } \\
\text { tropicum }\end{array}$ & $\begin{array}{c}\text { Pencillium } \\
\text { chryso }\end{array}$ & $\begin{array}{c}\text { Trichophyton } \\
\text { rubrum }\end{array}$ \\
\hline Methylcellulose & 45 & 26 & 70 & 50 & 52 \\
\hline Tylose & 37 & 19 & 60 & 50 & 46 \\
\hline Pluronic F-127 & 40 & 16 & 62 & 48 & 45 \\
\hline PVA & 32 & 16 & 47 & 37 & 38 \\
\hline Carbopol 974P & 40 & 24 & 64 & 58 & 51 \\
\hline Eudispert mv & 23 & 16 & 46 & 36 & 30 \\
\hline PEG & 70 & 35 & 72 & 60 & 64 \\
\hline $\begin{array}{l}\text { Control } \\
\text { (miconazol) }\end{array}$ & 30 & 16 & 15 & 0 & 22 \\
\hline
\end{tabular}

$0:$ no inhibition zone

\section{Conclusion}

- The in-vitro study is considered a useful methodology for screening Croconazol hydrochloride topical gel formulations.

- The release mechanism of the drug from the different gel formulations obeys diffusion mechanism.

- The amount of drug release of the drug depends on the nature of the polymer used for preparation of gel.

- There is a direct relationship between the amount of drug released from the pl. F-127 gel and the initial drug concentration and an inverse relationship with the concentration of the polymer.

- The Croconazol hydrochloride gel formulations show an excellent activity against different species of fungi.

\section{REFERENCES}

1- A. O. David and H. A. Anton, Topical delivery formulations. Ed., Marcel Dekker Inc. New York, 1990 pp. 1-20.

2- F. P. Bonna and L. Motenegro, Int. J. Pharm., 102, 19 (1994).

3- M. C. Rubio, A. Renzusta, J. G. Tomas and R. B. Ruesca, Rev. Ib. Micol., 16, 16 (1999).

4- J. De Lucca, and T. J. Waillsh, Antimicrobial Agents and Chemotherapy, 43, 1 (1999).

5- R. Spiewak, Int. Rev. Allergol. Clin., 6, 136 (2000).
6- R. Thesen, Pharm. Ztg., 30, 1120, (1995).

7- A. Doliwa, S. Satoyo and P. Ygarta, Drug Dev. Ind. Pharm., 27, 751 (2001).

8- Lu. Guangwei and Jun H. Won, Int. J. Pharm., 160, 1 (1998).

9- M. A. A. Kassem, S. Tayel and A. A. Osman, Egypt. J. Pharm. Sci., 33, 539 (1992).

10- A. M. Makky, ibid., 43, 1 (2002).

11- I. R. Schmalka and A. I. Artificial, J. Biomed. Matter. Res., 6, 571 (1972).

12- D. L. French, B. O. Haglund, K. J. Himmelstein, J. W. Mauger, Pharm. Res., 12, 1513 (1995).

13- J. Reineck, Topische Zuberitungen mit Croconazol und Vitamin A saure auf der Basis von Nanoemulsionen und Liposomen, Ph.D Thesis, Freiburg University, Germany (1998).

14- D. I. Nesseem, J. Pharm. Biom. Anaylsis, 26, 387 (2001)

15- A. Babar, U. D. Solanki, A. J. Cutie and F. Plakogiannis, Drug Dev. Ind. Pharm., 16, 523 (1990).

16- A. M. EL-Gendy, W. H. Jun and A. A.Kassem, ibid., 28, 823 (2002).

17- M. A. Hassan, F. A. Mohammed and E. A. Sabour, S.T.P Pharma Sci., 13, 195 (2003).

18- I. EL-Gibaly, F. A. Mohammed and M. Shehata, Pharm. Ind., 60, 1088 (1998). 